\title{
Correction: A Patient-Centered PaTH to Address Diabetes: Protocol for a Study on the Impact of Obesity Counseling
}

Jennifer L Kraschnewski ${ }^{1}$, MD, MPH; Lan Kong ${ }^{1}, \mathrm{PhD}$; Erica Francis ${ }^{1}$, MS; Hsin-Chieh Yeh $^{2}$, PhD; Cindy Bryce ${ }^{3}$, $\mathrm{PhD}$; Jennifer Poger ${ }^{1}$, MEd; Erik Lehman ${ }^{1}$, MS

\footnotetext{
${ }^{1}$ Penn State Health, College of Medicine, Penn State University, Hershey, PA, United States

${ }^{2}$ Johns Hopkins School of Medicine, Johns Hopkins University, Baltimore, MD, United States

${ }^{3}$ University of Pittsburgh, Department of Public Health, Pittsburgh, PA, United States
}

\section{Corresponding Author:}

Jennifer L Kraschnewski, MD, MPH

Penn State Health

College of Medicine

Penn State University

90 Hope Drive

Hershey, PA, 17033

United States

Phone: 17175317778

Email: jkraschnewski@pennstatehealth.psu.edu

\section{Related Article:}

Correction of: https://www.researchprotocols.org/2019/4/e12054/

(JMIR Res Protoc 2020;9(3):e17437) doi: 10.2196/17437

In the article "A Patient-Centered PaTH to Address Diabetes: Protocol for a Study on the Impact of Obesity Counseling" (JMIR Res Protoc 2019;8(4):e12054), there were three instances of incorrectly written code. The following corrections have been made:

In the Introduction section, under the subheading "Objectives", under the bullet point of "Aim 1", the code has been changed from "G0477" to "G0447". The text was revised from:

We will determine how the annual probability of receiving obesity counseling (as defined by Common Procedural Treatment [CPT] codes G0477, G0473, S9470, and/or S9449)

to:

We will determine how the annual probability of receiving obesity counseling (as defined by Common Procedural Treatment [CPT] codes G0447, G0473, S9470, and/or S9449)

In the Methods section, under the subheading "PaTH Patients With Diabetes and At Increased Risk for Diabetes", the code has been changed from "G0477" to "G0447". The text was revised from:

For this study, receipt of IBT will include the presence of the G0477, G0473, S9470, and/or S9449 CPT codes
For this study, receipt of IBT will include the presence of the G0447, G0473, S9470, and/or S9449 CPT codes

In the Methods section, under the subheading "Definition and Measurement of Key Diabetes Outcomes and Covariates", the code has been changed from "G0477" to "G0447". The text was revised from:

Receipt of counseling for obesity will be assessed through PaTH EHRs and supplemented by claims data when available, utilizing G0477, G0473, S9470, and/or S9449 CPT codes

to:

Receipt of counseling for obesity will be assessed through PaTH EHRs and supplemented by claims data when available, utilizing G0447, G0473, S9470, and/or S9449 CPT codes

These corrections do not impact the results or findings of the paper.

These corrections will appear in the online version of the paper on the JMIR Research Protocols website on March 4, 2020, together with the publication of this correction notice. Because this was made after submission to PubMed, PubMed Central, and other full-text repositories, the corrected article has also been resubmitted to those repositories.

to: 
This is a non-peer-reviewed article. Submitted 18.12.19; accepted 21.01.20; published 04.03.20.

Please cite as:

Kraschnewski JL, Kong L, Francis E, Yeh HC, Bryce C, Poger J, Lehman E

Correction: A Patient-Centered PaTH to Address Diabetes: Protocol for a Study on the Impact of Obesity Counseling

JMIR Res Protoc 2020;9(3):e17437

URL: https://www.researchprotocols.org/2020/3/e17437

doi: $\underline{10.2196 / 17437}$

PMID: $\underline{32133981}$

(CJennifer L Kraschnewski, Lan Kong, Erica Francis, Hsin-Chieh Yeh, Cindy Bryce, Jennifer Poger, Erik Lehman. Originally published in JMIR Research Protocols (http://www.researchprotocols.org), 04.03.2020. This is an open-access article distributed under the terms of the Creative Commons Attribution License (https://creativecommons.org/licenses/by/4.0/), which permits unrestricted use, distribution, and reproduction in any medium, provided the original work, first published in JMIR Research Protocols, is properly cited. The complete bibliographic information, a link to the original publication on http://www.researchprotocols.org, as well as this copyright and license information must be included. 